\title{
Comparison of Surgical and Conservative Management in 208 Patients with Acute Spinal Cord Injury
}

\author{
C.H. Tator, E.G. Duncan, V.E. Edmonds, L.I. Lapczak and D.F. Andrews
}

\begin{abstract}
The role of surgery in the management of acute spinal cord or cauda equina injuries remains controversial. The present study analyzed ten admission features and three outcome variables in 208 patients treated in an Acute Spinal Cord Injury Unit, $116(56 \%)$ of whom underwent at least one spinal operation. The surgical and non-surgical groups showed no significant differences in the following seven clinical features: age, sex, distance travelled to the Unit, time interval between trauma and admission, type of accident, severity of injuries to the spinal cord, and severity of associated injuries. However, the two groups showed significant differences in level and type of vertebral column injury, and in the frequency of pre-existing spinal abnormalities. These differences were due to management policies which selected certain injuries for surgical or non-surgical treatment. One-third of the operative procedures were performed primarily for neural decompression, one-third primarily for reduction of bony structures and one-third for fusion. However, $95 \%$ of the operative patients had a fusion at the initial operation. Operative treatment was associated with a lower overall mortality rate $(6.1 \%)$ than non-operative $(15.2 \%)$, despite a higher frequency of thrombo-embolic complications in the surgical group. Overall, there was no difference between operated and non-operated patients in length of stay or neurological recovery. Surgical management of patients with acute spinal cord injury appears safe in terms of mortality rate and neurological recovery, but it has not been proven to improve the latter.
\end{abstract}

RÉSUMÉ: Comparison entre le traitement chirurgical et le traitement conservateur chez 208 patients présentant une lésion aiguë de la moelle épinière Le rôle de la chirurgie dans le traitement des lésions aiguës de la moelle épinière ou de la queue de cheval demeure un sujet de controverse. Dans la présente étude, nous analysons dix éléments présents à l'admission et trois variables en rapport avec le résultat final chez 208 patients traités dans un unité de soins traitant les lésions aiguës de la moelle épinière, dont $116(56 \%)$ ont subi au moins une intervention chirurgicale à la moelle épinière. Il n'y avait pas de différence significative entre le groupe avec chirurgie et le groupe sans chirurgie en ce qui a trait aux sept éléments cliniques suivants: l'âge, le sexe, la distance séparant le patient de l'unité, l'intervalle entre le traumatisme et l'admission, le type d'accident, la sévérité des lésions de la moelle épinière et la sévérité des lésions associées. Cependant, il y avait une différence significative entre les deux groupes en ce qui concerne le niveau et le type de lésion de la colonne vertébrale, et dans la fréquence des anomalies spinales pré-existantes. Ces différences étaient dues à la ligne de conduite établie afin de déterminer quelles lésions étaient sélectionnées pour le traitement chirurgical ou non-chirurgical respectivement. Un tiers des interventions chirurgicales a été effectué essentiellement pour décompression nerveuse, un tiers principalement pour réduire des structures osseuses et un tiers pour fusion. Cependant, $95 \%$ des patients opérés ont eu une fusion lors de l'intervention initiale. Un taux de mortalité global plus bas $(6.1 \%)$ était associé au traitement opératoire par rapport au traitement non-opératoire $(15.2 \%)$ malgré une fréquence plus élevée de complications thrombo-emboliques dans le groupe avec chirurgie. Dans l'ensemble, il n'y avait pas de différence entre les patients opérés et non opérés quant à la longueur du séjour ou à la récupération neurologique. Le traitement chirurgical des patients avec une lésion aiguë de la moelle épinière semble sécuritaire en ce qui a trait au taux de mortalité et à la récupération neurologique, mais il n'est pas prouvé qu'il améliore cette dernière.

Can. J. Neurol. Sci. 1987; 14:60-69

From the Spinal Cord Injury Treatment. Research and Prevention Centre. Toronto Western Hospital and Department of Statistics, University of Toronto, Toronto. Ontario

Reprint requests to: C.H. Tator. Toronto Western Hospital, Suite 4034 Edith Cavell Wing, 399 Bathurst St., Toronto, Ontario, Canada M5T 2S8 
Since the end of the Second World War general principles of management for patients sustaining an acute spinal cord injury have been defined. The early institution of prophylactic measures to prevent systemic complications is combined with management of the spinal injury aimed at realignment of the vertebral column, relief of persisting compression of the cord or nerve roots, and restoration of a stable vertebral column. However, the place of surgery in achieving these goals remains controversial. Opinion regarding the efficacy of spinal surgery in acute cord injury ranges between two polarized schools of thought. At one end of the spectrum are clinicians who adhere to the tenets of Guttman, ' founder of Stoke Mandeville Hospital, England, and use closed, postural techniques combined with bedrest for 6 to 8 weeks to achieve reduction and fusion, only rarely resorting to surgery. At the other extreme are those, located principally in North America, who advocate early surgical intervention for reduction, decompression or stabilization, in some instances as soon as 3 hours after admission. ${ }^{2}$ The theoretical advantages claimed by proponents of spinal surgery in the acute phase are relief of residual neural compression to enhance the potential for recovery, and early stabilization of the vertebral column to decrease the period of bedrest prior to mobilization, the latter potentially reducing the complications associated with prolonged recumbency, shortening hospital stay and reducing the costs of management. Bedbrook's report in 1979, ${ }^{3}$ based on an extensive review of both schools of thought and personal experience, concluded that operative treatment has not been proven to be superior, although few studies provided definitive data.

One of the major difficulties in assessing surgical results is the identification of a suitable control group for statistical analysis. Two recent studies ${ }^{4.5}$ which address the controversy of surgical treatment of acute spinal cord injuries analyzed the results of operative versus non-operative management in concurrently treated patients. Ahn et al ${ }^{4}$ retrospectively examined the management of 1,385 patients with cord injury due to high thoracic and thoracolumbar spinal fractures registered with the National Spinal Cord Injury Data Research Centre between 1973 and 1979. They found little change in the proportion of patients managed surgically over the period of the study, approximately $75 \%$, but identified significant changes in the types of procedures performed, especially the increased number of Harrington rod instrumentations which, in the latter part of the study period accounted for almost $50 \%$ of all procedures. They concluded that these changes had improved health care because the two predominant surgical treatments, Harrington instrumentation with fusion (24.4\%) and laminectomy combined with Harrington instrumentation and fusion $(23.2 \%)$ were associated with the shortest hospital stay in both the acute and rehabilitation settings. Wilmot and $\mathrm{Hall}^{5}$ retrospectively analyzed the management of 95 consecutive patients with cord injury admitted to a rehabilitation service and compared complication rates, neurological recovery and length of stay in the surgical (75.8\%) and non-surgical $(24.2 \%)$ groups. Over two thirds $(69.4 \%)$ of the surgical procedures involved Harrington instrumentation and posterior bony fusion. Patients treated surgically showed no significant shortening of rehabilitation stay, although their combined acute and rehabilitation stay was significantly shortened. Neurological recovery was not altered by surgery but operative treatment was associated with an increased incidence of complications, thrombophlebitis being the most common followed by pulmonary embolism.
Although these two studies compared concurrently treated surgical and non-surgical groups, neither incorporated random allocation of patients to treatment modality or comprehensive characterization of the control and therapeutic groups. For example, there was no analysis of admission parameters to identify any initial variation between the two treatment groups which may have contributed to the observed differences in outcome.

The present study analyzes a series of 208 patients with acute spinal cord injury admitted to a specialized spinal cord injury unit. Although the study was performed prospectively, patients were not randomly allocated to the two treatment groups, surgical or conservative. However, rigorous statistical analysis, including multiple regression techniques, were used to compare the entrance characteristics of the two groups and to analyse the outcomes. For example, the two groups were compared with respect to 10 admission parameters and outcome was analyzed according to morbidity, mortality, neurological recovery and length of first hospitalization. In this way any differences in outcome could be attributed to either differences in admission parameters or to differences in treatment.

\section{Materials and Methods}

The first 220 consecutive patients admitted to the Acute Spinal Cord Injury Unit at Sunnybrook Medical Centre, Toronto, between 1974, when the unit was established, and 1981 were considered for entry into this study. For inclusion patients must have been admitted to the Unit within 30 days of injury and have had no operative treatment in other institutions before referral. Patients sustaining spinal column injury without cord involvement or with nerve root injury only were excluded. The only patient in this series with a penetrating injury was also excluded, so that all patients in the study had a closed cord injury. Based on these criteria, 208 patients were included in the study. Data were collected prospectively according to a predetermined protocol by observers not directly involved in management decisions and patient care. Some of the demographic details of the group were described in a companion paper $^{6}$ which included only the 201 patients with cord injuries, whereas the present group includes seven additional patients with injuries to the lumbo-sacral spine and cauda equina. The patients were treated by one of three neurosurgeons under whom they were admitted with the active involvement of orthopaedic consultants. Therapeutic decisions were made according to generally accepted principles ${ }^{7}$ rather than to a predetermined protocol. In general, cervical injuries were treated initially by halo traction followed by mobilization in a halo vest. Application of halos or skull tongs was not considered a surgical procedure for the purposes of this study. Operation was considered for patients showing neurological deterioration or lack of improvement who had radiological evidence of compromise of the spinal canal or malalignment of the vertebral column which could not be reduced or maintained reduced by closed methods. For patients with injuries of the thoracic, thoracolumbar or lumbosacral spine initial management was bedrest with postural reduction. Surgical intervention was considered for neurological deterioration or lack of improvement with radiological evidence of spinal canal compromise, failure to achieve reduction or, following stabilization of the patient's general condition, to achieve immediate rigid internal fixation to permit early mobilization. 
Data on demography, type and severity of spinal and nonspinal injury, treatment, complications and outcome at discharge were gathered prospectively by the authors. Follow-up data were obtained by outpatient review, chart review, or by contacting practitioners involved in ongoing supervision of the patients or directly from the patients or relatives. In a previous study of cord injury ${ }^{8}$ we used follow-up periods of 12 or 18 months for patients with complete or incomplete cord injuries, respectively. However, we found no significant new neurological improvement below the injury level after 6 or 12 months in complete or incomplete injuries, respectively, and therefore, these shorter follow-up intervals were used in the present study. Neurological recovery was assessed using the 17 point neurological recovery scale previously described. ${ }^{8}$ Associated injuries were described using the Injury Severity Score (ISS) described by Baker et al ${ }^{9}$ and calculated according to the abbreviated method of Greenspan et al. ${ }^{10}$ The severity of the spinal cord injury is also reflected by the ISS. The information was initially coded on standardized forms and then entered into the computer for processing at the University of Toronto Computer Centre using the Statistical Package for the Social Sciences (SPSS). Standard statistical methods, including multiple regression techniques, were employed for data analysis. Earlier reports have described the methodology in detail and have included some of the preliminary results. ${ }^{811-22}$

\section{Results}

Of the 208 patients, $116(55.8 \%)$ underwent at least one spinal operative procedure and will be referred to as the "operated group". The remaining $92(44.2 \%)$ had no spinal surgery during the first hospital admission, or with one exception, during the follow-up period for the management of the spinal injury, and are called the "non-operated group". The exception was a patient with a complete cervical cord injury successfully managed with halo vest external fixation who subsequently required Harrington rod instrumentation at 13 months after injury to correct a progressive thoracolumbar scoliosis secondary to the cord injury. Many patients in both groups had non-spinal surgical procedures such as tracheostomy, laparotomy or operative reduction of limb fractures.

Five patients in the operated group required a second spinal operation, the time interval between the two procedures ranging from 24 hours to 7 months. The reasons for the second operations included persisting compression or instability in four, with the second operation performed from an alternative surgical approach, and in one patient a post-operative haematoma. For the present study these 5 patients were coded according to their first operation.

The relationship between surgical and non-surgical management and the ten admission variables, complication rates, mortality rates, length of stay, and neurological recovery are described in the following tables and summarized with an appropriate statistical test. However, each parameter identified is not entirely independent, and the significance of any individual test should be interpreted in the context of these multiple summaries.

Table 1 shows the sex and age of the operated and nonoperated groups. The proportion of females in the non-operated group was slightly higher, although the difference was not statistically significant $\left(X^{2}, p=0.49\right)$. The mean and median ages of the operated group ( 32.5 and 24.5 years, respectively)
Table 1: Sex and Age of Operated and Non-Operated Groups

\begin{tabular}{|c|c|c|c|}
\hline Sex & Operated (\%) & $\begin{array}{c}\text { Non- } \\
\text { Operated (\%) }\end{array}$ & Total \\
\hline & $(n=116)$ & $(n=92)$ & $(n=208)$ \\
\hline $\begin{array}{l}\text { Male } \\
\text { Female }\end{array}$ & $\begin{array}{l}81.0 \\
19.0\end{array}$ & $\begin{array}{l}76.1 \\
23.9\end{array}$ & $\begin{array}{l}78.8 \\
21.2\end{array}$ \\
\hline $\begin{array}{l}\text { Ratio } \\
\text { Male:Female }\end{array}$ & $4.3: 1$ & $3.2: 1$ & $3.7: 1$ \\
\hline
\end{tabular}

\begin{tabular}{llll} 
Age (Yr.) & & & \\
Mean & 32.5 & 37.0 & 34.4 \\
Median & 24.5 & 28.0 & 27.0 \\
Mode & 19.0 & 19.0 & 19.0 \\
Minimum & 14.0 & 12.0 & 12.0 \\
Maximum & 86.0 & 90.0 & 90.0 \\
\hline
\end{tabular}

Table 2: Relationship Between Accident Type and Treatment Modality

\begin{tabular}{|c|c|c|c|c|}
\hline \multirow[t]{3}{*}{$\begin{array}{l}\text { Accident } \\
\text { Category } \\
\end{array}$} & $\begin{array}{c}\text { Number } \\
\text { of Cases }\end{array}$ & $\frac{\text { Operated }}{(n=116)}$ & $\frac{\begin{array}{c}\text { Non- } \\
\text { Operated }\end{array}}{(n=92)}$ & $\frac{\text { Total }}{(n=208)}$ \\
\hline & & Row \% & Row \% & Row \% \\
\hline & & Column $\%$ & Column $\%$ & Column \% \\
\hline $\begin{array}{l}\text { Motor } \\
\text { Vehicle }\end{array}$ & 86 & $\begin{array}{l}55.8 \\
41.4\end{array}$ & $\begin{array}{l}44.2 \\
41.3\end{array}$ & $\begin{array}{r}100.0 \\
41.3\end{array}$ \\
\hline $\begin{array}{l}\text { Sport and } \\
\text { Recreation }\end{array}$ & 47 & $\begin{array}{l}46.8 \\
19.0\end{array}$ & $\begin{array}{l}53.2 \\
27.2\end{array}$ & $\begin{array}{r}100.0 \\
22.6\end{array}$ \\
\hline Work & 29 & $\begin{array}{l}75.9 \\
19.0\end{array}$ & $\begin{array}{r}24.1 \\
7.5\end{array}$ & $\begin{array}{r}100.0 \\
13.9\end{array}$ \\
\hline Domestic & 25 & $\begin{array}{l}56.0 \\
12.1\end{array}$ & $\begin{array}{l}44.0 \\
12.0\end{array}$ & $\begin{array}{r}100.0 \\
12.0\end{array}$ \\
\hline Other & 21 & $\begin{array}{r}52.4 \\
8.5 \\
\end{array}$ & $\begin{array}{l}47.6 \\
12.0 \\
\end{array}$ & $\begin{array}{r}100.0 \\
10.2 \\
\end{array}$ \\
\hline Column Total & $\overline{208}$ & $\overline{100.0}$ & $\overline{100.0}$ & $\overline{100.0}$ \\
\hline
\end{tabular}

were slightly younger than the non-operated (37.0 and 28.0 years, respectively), although these differences were not significant (2-tail T-test, pooled variance estimate, $p=0.086$ ).

The types of accidents causing the spinal cord injuries in the two groups are shown in Table 2. Motor vehicle accident victims included occupants of cars and trucks, motorcycle and bicycle riders and pedestrians. The "other" category included many diverse causes such as assault, suicide attempt and train and aircraft accidents. Motor vehicle accidents were the commonest cause of spinal cord injury (41.3\%) and sportsrecreational accidents were second (22.6\%). Overall, there was no significant difference between the two groups in the proportion of injuries caused by the different accident types $\left(X^{2}\right.$, $\mathrm{p}=0.14)$. Indeed, for each accident type except work, about half the patients were treated with, and half without spinal surgery. In the work category $75.9 \%$ underwent operation.

Table 3 shows the level of the vertebral column injury and the influence of this variable on selection for surgical treatment. There was a highly significant relationship between level of injury and treatment $\left(\mathrm{X}^{2}, \mathrm{p}<0.001\right)$ : approximately $45 \%$ of patients with cervical injuries had surgery, whereas below this level at least $70 \%$ of the patients had surgery. As the site of injury progressed caudally, the proportion of cases undergoing surgical treatment increased. 
Table 3: Effect of Level of Spinal Injury on Selection for Surgical or Non-Surgical Treatment

\begin{tabular}{|c|c|c|c|c|}
\hline \multirow[t]{4}{*}{$\begin{array}{l}\text { Level of } \\
\text { Injury }\end{array}$} & $\begin{array}{l}\text { Number } \\
\text { of Cases } \\
\end{array}$ & Operated & $\begin{array}{c}\text { Non- } \\
\text { Operated } \\
\end{array}$ & Total \\
\hline & $(n)$ & $(n=116)$ & $(n=92)$ & $(n=208)$ \\
\hline & & Row \% & Row \% & Row $\%$ \\
\hline & & $\overline{\text { Column } \%}$ & Column \% & Column $\%$ \\
\hline $\begin{array}{l}\text { Cervical } \\
\quad(\mathrm{Cl} \text { to } \mathrm{C} 7-\mathrm{T} 1)\end{array}$ & 127 & $\begin{array}{l}43.3 \\
47.4\end{array}$ & $\begin{array}{l}56.7 \\
78.3\end{array}$ & $\begin{array}{r}100.0 \\
61.1\end{array}$ \\
\hline $\begin{array}{l}\text { Thoracic } \\
\text { (T1 to T11) }\end{array}$ & 34 & $\begin{array}{l}70.6 \\
20.7\end{array}$ & $\begin{array}{l}29.4 \\
10.8\end{array}$ & $\begin{array}{r}100.0 \\
16.3\end{array}$ \\
\hline $\begin{array}{l}\text { Thoraco-Lumbar } \\
\text { (T11-12 to L1-2) }\end{array}$ & 40 & $\begin{array}{l}77.5 \\
26.7\end{array}$ & $\begin{array}{r}22.5 \\
9.8\end{array}$ & $\begin{array}{r}100.0 \\
19.2\end{array}$ \\
\hline $\begin{array}{l}\text { Lumbo-Sacral } \\
\text { (L2 to S5) }\end{array}$ & 7 & $\begin{array}{r}85.7 \\
5.2\end{array}$ & $\begin{array}{r}14.3 \\
1.1\end{array}$ & $\begin{array}{r}100.0 \\
3.4\end{array}$ \\
\hline Column Total & 208 & 100.0 & 100.0 & 100.0 \\
\hline
\end{tabular}

The vertebral column injuries were divided into five types according to a previously described classification ${ }^{23}$ and Table 4 shows the relationship between these types and the selection of treatment. There was a highly significant association between the type of bony injury and the treatment modality $\left(X^{2}, p<0.001\right)$. Patients without radiological evidence of vertebral column injury (classified as "normal'), those with dislocations without fracture and those with only minor bony injuries (body, pedicle, facet or spinous process fractures, classified as "other") had the lowest rates of operation. Indeed, no patient with dislocation without fracture required operation and only $26.7 \%$ of patients with "normal" vertebral x-rays and only $28.6 \%$ of patients with minor fractures required surgery. In contrast, $60 \%$ of patients with fracture-dislocations or burst fractures had spinal surgery, and those with compression fractures had the highest rate of operation $(76.9 \%)$.

Table 5 compares the severity of the cord injury at admission in the operated and non-operated groups, according to the ten point Spinal Cord Injury Severity Scale, described previously. ${ }^{8}$ Grade 1 represents a complete cord injury with no motor or sensory function below the level of the lesion, Grades 2 to 9 represent decreasing degrees of severity of incomplete cord injury (at Grade 7 a patient has sufficient strength to walk), and Grade 10 indicates normal motor and sensory function. Most Grade 10 patients had spinal concussion with neurological deficits which resolved during the interval between the accident and admission to hospital. There was no significant difference in severity of cord injury on admission between the operated and non-operated groups (2-tail T-test, pooled variance estimate, $\mathrm{p}=0.79$ ). In both treatment groups approximately $45 \%$ of patients sustained complete cord injuries and 55\% had incomplete injuries.

Radiological examination revealed pre-existing conditions affecting the vertebral column in 35 patients $(17.0 \%$ ) (Table 6). Of these, 27 had a single abnormality identified, and eight had two conditions. The most common was cervical spondylosis (23 patients, $11.0 \%$ ), either alone (17 patients, $8.1 \%$ ) or in combination with a congenital fusion or other congenital bony abnormality (6 patients, $2.9 \%$ ). The next most common was ankylosing spondylitis in four patients $(2.0 \%)$. Four patients had a congenital fusion without associated spondylosis. Of the 35 patients with pre-existing spinal conditions $22(62.9 \%)$ were treated non-operatively and $13(37.1 \%)$ underwent spinal surgery, a significant difference $\left(X^{2}, p=0.025\right)$.
The patients with pre-existing spinal conditions differed markedly from the others in age, type of accident causing the spinal injury, level of injury, type of vertebral column injury and severity of cord injury. Thirty $(85.7 \%)$ of these 35 patients were 51 years of age or older and comprised $65.2 \%$ of the total of 46 patients over 51 years of age in the study population. By comparison, $81.6 \%$ of the patients without vertebral column disease were 40 years of age or younger. The most common cause of injury in the pre-existing condition group was a domestic accident, usually a fall, which accounted for $15(42.9 \%)$ of the injuries while this type of accident was the least common of the five types of accident category in those without pre-existing conditions, affecting only $5.8 \%$. The majority of patients with pre-existing spinal conditions suffered a cervical injury $(88.6 \%)$ as opposed to $55.7 \%$ with cervical injuries in the other patients. Patients with pre-existing conditions showed less disruption of the vertebral column, with $28.6 \%$ having normal radiographs

Table 4: Effect of Type of Bony Injury to Vertebral Column on Selection for Surgical or Non-Surgical Treatment

\begin{tabular}{|c|c|c|c|c|}
\hline \multirow[t]{4}{*}{$\begin{array}{l}\text { Type of } \\
\text { Bony Injury } \\
\end{array}$} & $\begin{array}{l}\text { Number } \\
\text { of Cases }\end{array}$ & Operated & $\begin{array}{c}\text { Non- } \\
\text { Operated } \\
\end{array}$ & Total \\
\hline & (n) & $(n=116)$ & $(n=92)$ & $(n=208)$ \\
\hline & & Row \% & Row \% & Row \% \\
\hline & & Column $\%$ & Column $\%$ & Column $\%$ \\
\hline Normal & 15 & $\begin{array}{r}26.7 \\
3.4\end{array}$ & $\begin{array}{l}73.3 \\
12.0\end{array}$ & $\begin{array}{r}100.0 \\
7.2\end{array}$ \\
\hline Dislocation Only & 6 & $\begin{array}{l}0.0 \\
0.0\end{array}$ & $\begin{array}{r}100.0 \\
6.5\end{array}$ & $\begin{array}{r}100.0 \\
2.9\end{array}$ \\
\hline $\begin{array}{l}\text { Fracture- } \\
\text { Dislocation }\end{array}$ & 88 & $\begin{array}{l}63.6 \\
48.4\end{array}$ & $\begin{array}{l}36.4 \\
34.7\end{array}$ & $\begin{array}{r}100.0 \\
42.3\end{array}$ \\
\hline Compression & 13 & $\begin{array}{r}76.9 \\
8.6\end{array}$ & $\begin{array}{r}23.1 \\
3.3\end{array}$ & $\begin{array}{r}100.0 \\
6.3\end{array}$ \\
\hline Burst & 72 & $\begin{array}{l}58.3 \\
36.2\end{array}$ & $\begin{array}{l}41.7 \\
32.6\end{array}$ & $\begin{array}{r}100.0 \\
34.6\end{array}$ \\
\hline Other & 14 & $\begin{array}{r}28.6 \\
3.4 \\
\end{array}$ & $\begin{array}{l}71.4 \\
10.9 \\
\end{array}$ & $\begin{array}{r}100.0 \\
6.7 \\
\end{array}$ \\
\hline Column Total & $\overline{208}$ & 100.0 & 100.0 & 100.0 \\
\hline
\end{tabular}

Table 5: Relationship Between Severity of Spinal Cord Injury* and Selection for Surgical or Non-Surgical Treatment

\begin{tabular}{|c|c|c|c|c|}
\hline \multirow[t]{2}{*}{$\begin{array}{l}\text { Grade on } \\
\text { Admission } \\
\end{array}$} & \multirow{2}{*}{$\begin{array}{l}\begin{array}{l}\text { Number } \\
\text { of Cases }\end{array} \\
(n)\end{array}$} & \multirow{2}{*}{$\frac{\text { Operated }}{(n=116)} \frac{(\%)}{}$} & \multirow{2}{*}{$\frac{\begin{array}{c}\text { Non- } \\
\text { Operated }\end{array}}{(\mathrm{n}=92)}$} & \multirow{2}{*}{$\frac{\text { Total }}{(n=208)} \frac{(\%)}{(\%)}$} \\
\hline & & & & \\
\hline 1 & 93 & 44.8 & 44.6 & 44.7 \\
\hline 2 & 31 & 16.4 & 13.0 & 14.8 \\
\hline 3 & 0 & 0.0 & 0.0 & 0.0 \\
\hline 4 & 17 & 5.2 & 12.0 & 8.2 \\
\hline 5 & 0 & 0.0 & 0.0 & 0.0 \\
\hline 6 & 2 & 1.7 & 0.0 & 1.0 \\
\hline 7 & 49 & 25.8 & 20.7 & 23.6 \\
\hline 8 & 9 & 4.3 & 4.3 & 4.3 \\
\hline 9 & 2 & 0.9 & 1.1 & 1.0 \\
\hline 10 & 5 & 0.9 & 4.3 & 2.4 \\
\hline Total & 208 & 100.0 & 100.0 & $\overline{100.0}$ \\
\hline \multirow{2}{*}{\multicolumn{2}{|c|}{$\begin{array}{c}1 \text { (Complete) } \\
2-10 \text { (Incomplete) }\end{array}$}} & 44.8 & 44.6 & $\begin{array}{l}44.7 \\
55.3\end{array}$ \\
\hline & & & 55.4 & 55.3 \\
\hline \multicolumn{2}{|l|}{ Total } & 100.0 & 100.0 & 100.0 \\
\hline
\end{tabular}

* Spinal Cord Injury Severity Scale: Grade 1 = A complete injury with total motor and sensory loss below the level of the lesion; Grades 2.9 $=$ Varying degrees of incomplete injury; and Grade $10=$ Normal: $(8)$. 
Table 6: Pre-Existing Vertebral Column Conditions in the Operated and Non-Operated Groups

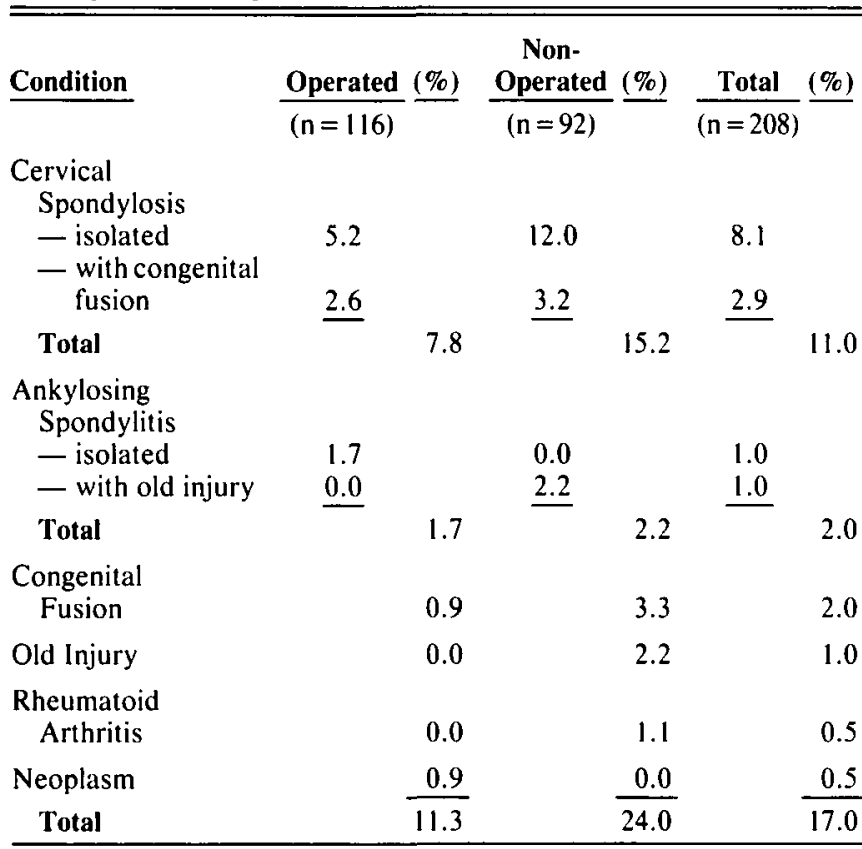

(compared to $2.9 \%$ in the remainder of the patients), and $20.0 \%$ had only minor fractures such as pedicle, lamina or body fractures (compared to $4.0 \%$ of the remaining patients). Burst fractures accounted for only $5.7 \%$ of cases in the patients with pre-existing disease as opposed to $40.5 \%$ in the others, while fracture-dislocation (37.1\% and $43.4 \%$, respectively) and compression fractures (5.7\% and $6.4 \%$ respectively) were equally common in the two groups. Patients with pre-existing spinal abnormalities showed less severe cord injuries with $82.9 \%$ having incomplete injuries as compared to $49.7 \%$ for the remaining patients.

The mean ISS for the operated group was 24.6 and for the non-operated group 24.8 (Table 7), and these were not significantly different (2-tailed T-test, pooled variance estimate, $p=0.88$ ). Surgery was delayed in three patients due to their general medical condition, but in no patient did the associated injuries prevent operative treatment.

There was no significant difference $\left(X^{2}, p=0.19\right)$ between the two groups in the distance from the accident site to the Acute Spinal Cord Injury Unit (Table 8). Table 9 shows the time intervals between the accidents and admission to the Acute Spinal Cord Injury Unit, and again there was no significant difference between the two groups (2-tail T-test, pooled variance estimate, $p=0.44)$. Thus, the two groups travelled similar distances to reach the Unit with similar delays.

The primary indication for surgery in the operated patients is shown in Table 10. Approximately one-third of the patients were operated on for decompression of the spinal cord or nerve roots, one-third for reduction of malalignment, and one-third for fusion of the vertebral column. When the principal indication for surgery was examined in relationship to the severity of the spinal cord injury there was no significant difference between complete and incomplete injuries $\left(\mathrm{X}^{2}, \mathrm{p}=0.13\right)$. When each indication was examined with respect to severity of cord injury there was no difference in the frequency of reductions or fusions, but incomplete cases had approximately twice the frequency of decompressions compared with complete cases.
Table 7: Injury Severity Score (ISS) in the Operated and Non-Operated Groups

\begin{tabular}{|c|c|c|c|c|}
\hline$\underline{\text { ISS }}$ & $\begin{array}{l}\text { Number } \\
\text { of Cases }\end{array}$ & Operated (\%) & $\begin{array}{c}\text { Non- } \\
\text { Operated (\%) }\end{array}$ & Total $(\%)$ \\
\hline & (n) & $\overline{(n=116)}$ & $(n=92)$ & $\overline{(n=208)}$ \\
\hline $1-10$ & 2 & 0.0 & 2.2 & 1.0 \\
\hline $11-20$ & 88 & 43.1 & 41.3 & 42.3 \\
\hline $21-30$ & 82 & 39.7 & 39.1 & 39.4 \\
\hline $31-40$ & 21 & 11.2 & 8.7 & 10.1 \\
\hline $41-50$ & 13 & 6.0 & 6.5 & 6.2 \\
\hline $51-60$ & $\underline{2}$ & 0.0 & 2.2 & 1.0 \\
\hline Total & 208 & 100.0 & 100.0 & 100.0 \\
\hline $\begin{array}{l}\text { Mean } \\
\text { ISS }\end{array}$ & & 24.6 & 24.8 & 24.7 \\
\hline
\end{tabular}

Table 8: Distances From Site of Accident to Acute Spinal Cord Injury Unit in the Operated and Non-Operated Groups

\begin{tabular}{|c|c|c|c|c|}
\hline $\begin{array}{l}\text { Distance } \\
\text { [Miles] } \\
\end{array}$ & $\begin{array}{l}\text { Number } \\
\text { of Cases }\end{array}$ & Operated (\%) & $\begin{array}{l}\text { Non- } \\
\text { Operated (\%) }\end{array}$ & Total $(\%)$ \\
\hline & (n) & $(n=116)$ & $(n=92)$ & $(\mathrm{n}=208)$ \\
\hline$<10$ & 70 & 30.1 & 38.0 & 33.6 \\
\hline $10-24$ & 21 & 6.0 & 15.2 & 10.1 \\
\hline $25-49$ & 38 & 23.3 & 12.0 & 18.3 \\
\hline $50-74$ & 47 & 22.4 & 22.9 & 22.6 \\
\hline $75-149$ & 14 & 7.8 & 5.4 & 6.7 \\
\hline$>149$ & 16 & 9.5 & 5.4 & 7.7 \\
\hline $\begin{array}{l}\text { Outside } \\
\text { Ontario }\end{array}$ & 2 & 0.9 & 1.1 & 1.0 \\
\hline Total & 208 & 100.0 & 100.0 & 100.0 \\
\hline
\end{tabular}

Table 9: Time Interval From Accident to Admission to Acute Spinal Cord Injury Unit

\begin{tabular}{|c|c|c|c|c|}
\hline $\begin{array}{l}\text { Time } \\
\text { Interval } \\
\text { [Hours] } \\
\end{array}$ & $\begin{array}{l}\text { Number } \\
\text { of Cases }\end{array}$ & Operated $(\%)$ & $\begin{array}{l}\text { Non- } \\
\text { Operated (\%) }\end{array}$ & Total $(\%)$ \\
\hline & (n) & $\overline{(n=116)}$ & $(n=92)$ & $\overline{(n=208)}$ \\
\hline $0-6$ & 135 & 60.3 & 70.6 & 64.9 \\
\hline $7-12$ & 29 & 14.7 & 13.0 & 13.9 \\
\hline $13-24$ & 15 & 7.8 & 6.5 & 7.2 \\
\hline $25-48$ & 11 & 6.9 & 3.3 & 5.3 \\
\hline $49-96$ & 6 & 3.4 & 2.2 & 2.9 \\
\hline$>96$ & 12 & 6.9 & 4.4 & 5.8 \\
\hline Total & 208 & 100.0 & 100.0 & 100.0 \\
\hline \multicolumn{5}{|c|}{$\begin{array}{l}\text { Table 10: Primary Indication for Surgery in } 116 \text { Operated Cases } \\
\text { Related to Severity of Cord Injury }\end{array}$} \\
\hline \multirow[t]{2}{*}{ Indication } & $\begin{array}{l}\text { Number } \\
\text { of Cases }\end{array}$ & $\begin{array}{l}\text { Complete } \\
\text { Cord } \\
\text { Injury } \quad(\%) \\
\end{array}$ & $\begin{array}{l}\text { Incomplete } \\
\text { Cord } \\
\text { Injury } \quad(\%) \\
\end{array}$ & Total \\
\hline & $(n)$ & $(n=52)$ & $(n=64)$ & $\overline{(n=116)}$ \\
\hline $\begin{array}{l}\text { Decom- } \\
\text { pression }\end{array}$ & 41 & 25.0 & 43.8 & 34.7 \\
\hline Reduction & 34 & 36.5 & 23.4 & 28.8 \\
\hline Fusion & 41 & 38.5 & 32.8 & 34.7 \\
\hline Total & 116 & 100.0 & 100.0 & 100.0 \\
\hline
\end{tabular}


One hundred and eleven ( $95.7 \%$ ) of the 116 operated patients had a spinal fusion with their first spinal operation (Table 11). Of the 41 patients operated on primarily to achieve decompression, $36(87.8 \%)$ also had a fusion, and all $34(100 \%)$ who underwent operative reduction also had a fusion at the time of their first surgery. Of the five patients who did not undergo an operative fusion at the time of their first operation, four had a decompressive laminectomy and one had a laminectomy for decompression and perfusion of the spinal cord.

Figure 1 shows the timing of the surgical procedures and indicates that $56(48.2 \%)$ of the operations were performed in the first week following injury. By the end of the fourth week after injury $100(86.2 \%)$ of the patients ultimately undergoing surgery had had their operation. The timing for complete and incomplete cases was almost identical.

The relationship between the timing of the operations and the primary indication for surgery is examined in Table 12. In the first week the most frequent indication for operation was decompression which accounted for $51.8 \%$ of the procedures, the remaining operations in the first week being divided almost equally between reduction and fusion of the vertebral column. In the following weeks the number of decompressions was sharply reduced. The number of procedures primarily for fusion

Table 11: Primary Indication for Surgery in 111 Patients

Undergoing Spinal Fusion

\begin{tabular}{|c|c|c|c|c|}
\hline $\begin{array}{l}\text { Principal } \\
\text { Indication } \\
\text { for Surgery }\end{array}$ & $\begin{array}{c}\text { Number of } \\
\text { Patients } \\
\end{array}$ & $\begin{array}{c}\text { Number of } \\
\text { Patients With } \\
\text { Fusion } \\
\end{array}$ & $\begin{array}{c}\% \text { of } \\
\text { Patients }\end{array}$ & $\begin{array}{l}\% \text { of All } \\
\text { Fusions }\end{array}$ \\
\hline $\begin{array}{l}\text { Decom- } \\
\text { pression }\end{array}$ & 41 & 36 & 87.8 & 32.4 \\
\hline Reduction & 34 & 34 & 100.0 & 30.6 \\
\hline Fusion & 41 & 41 & 100.0 & 37.0 \\
\hline Total & 116 & 111 & & 100.0 \\
\hline
\end{tabular}

increased after the first week, and thereafter, fusion was the most common indication for surgery.

The operative approaches and procedures in the 116 patients are summarized in Table 13. The majority (75.0\%) of procedures were performed via a posterior approach with fusion being the most common operative procedure performed from this approach. Indeed, posterior fusion was also the single most common procedure and was performed on $32.8 \%$ of the operated patients. Reduction and fusion from a posterior approach was the second most common procedure (23.3\%). Decompressive laminectomy alone was performed on only 5 of the patients (4.3\%), while decompressive laminectomy combined with fusion was performed on 12 patients (10.3\%); decompressive laminectomy, reduction and fusion was performed in $4.3 \%$ of cases. The anterior approach was used in $25 \%$ of cases, the majority for decompression and fusion (21.6\%), and the remainder for

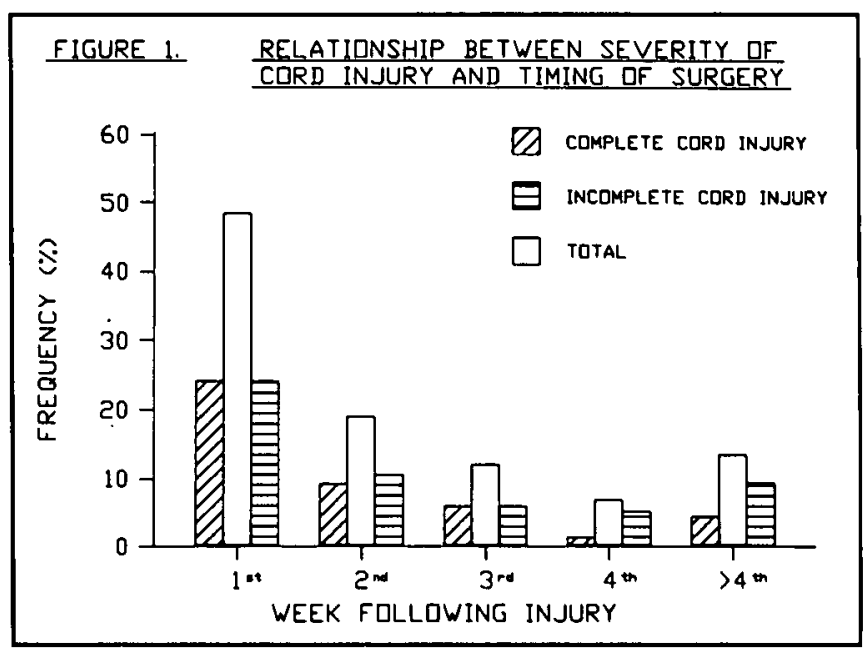

Figure 1-The timing of surgery shown for complete, incomplete and the total group of injuries as a $\%$ of the total number of operations.

Table 12: Primary Indication for Surgery in Relation to Severity of Cord Injury and Timing of Operation for 116 Operated Patients

\begin{tabular}{|c|c|c|c|c|c|c|c|c|}
\hline Sub-Total & & 25.0 & & 13.8 & & 9.4 & & 48.2 \\
\hline $\begin{array}{l}\text { Week } 2 \\
\text { Complete } \\
\text { Incomplete }\end{array}$ & $\begin{array}{l}0.9 \\
2.6\end{array}$ & & $\begin{array}{l}3.5 \\
1.7\end{array}$ & & $\begin{array}{l}4.3 \\
6.0\end{array}$ & & $\begin{array}{r}8.6 \\
10.4\end{array}$ & \\
\hline Sub-Total & & 3.5 & & 5.2 & & 10.3 & & 19.0 \\
\hline $\begin{array}{l}\text { Week } 3 \\
\text { Complete } \\
\text { Incomplete }\end{array}$ & $\begin{array}{l}0.0 \\
1.7\end{array}$ & & $\begin{array}{l}2.6 \\
1.7\end{array}$ & & $\begin{array}{l}3.4 \\
2.6\end{array}$ & & $\begin{array}{l}6.0 \\
6.0\end{array}$ & \\
\hline Sub-Total & & 1.7 & & 4.3 & & 6.0 & & 12.0 \\
\hline $\begin{array}{l}>\text { Week } 4 \\
\text { Complete } \\
\text { Incomplete }\end{array}$ & $\begin{array}{l}0.0 \\
2.6\end{array}$ & & $\begin{array}{l}1.7 \\
3.5\end{array}$ & & $\begin{array}{l}2.6 \\
3.5\end{array}$ & & $\begin{array}{l}4.4 \\
9.5\end{array}$ & \\
\hline Sub-Total & & 2.6 & & 5.2 & & 6.1 & & 13.9 \\
\hline Total & & 35.4 & & 29.4 & & 35.2 & & 100.0 \\
\hline
\end{tabular}


Table 13: Operative Approaches and Procedures Performed in

116 Patients

\begin{tabular}{|c|c|c|c|c|}
\hline Procedure & $\begin{array}{c}\text { Number } \\
\text { of Patients }\end{array}$ & & $\begin{array}{c}\% \\
\text { of Totals } \\
\end{array}$ & \\
\hline \multicolumn{5}{|l|}{ Posterior Approach } \\
\hline Fusion & 38 & & 32.8 & \\
\hline Reduction and fusion & 27 & & 23.3 & \\
\hline $\begin{array}{l}\text { Decompression by } \\
\text { laminectomy and fusion }\end{array}$ & 12 & & 10.3 & \\
\hline $\begin{array}{l}\text { Decompression by } \\
\text { laminectomy alone }\end{array}$ & 5 & & 4.3 & \\
\hline \multirow[t]{2}{*}{$\begin{array}{l}\text { Decompression by } \\
\text { laminectomy, reduction } \\
\text { and fusion }\end{array}$} & 5 & & 4.3 & \\
\hline & & 87 & & 75.0 \\
\hline \multicolumn{5}{|l|}{ Anterior Approach } \\
\hline $\begin{array}{l}\text { Decompression by removal } \\
\text { of vertebral body and fusion }\end{array}$ & 25 & & 21.6 & \\
\hline \multirow[t]{2}{*}{ Fusion } & 4 & & 3.4 & \\
\hline & & 29 & & 25.0 \\
\hline Total & & 116 & & 100.0 \\
\hline
\end{tabular}

fusion alone (3.4\%). Forty-three patients had Harrington rod instrumentation for stabilization of thoracic and lumbar fractures, and this represents $72.9 \%$ of the 59 patients with injuries to the thoracic spine or lower who had a spinal operation.

Ninety (43.3\%) of the 208 patients were managed with halo vest external fixation, $51(56.7 \%)$ in the non-operated group and $39(43.3 \%)$ in the operated group. One patient with a cervical fracture without associated cord injury was treated successfully in a halo vest while internal fixation was performed for his thoracic injury with associated cord lesion.

Five categories of complications were analyzed (Table 14). A respiratory complication was defined as one episode of atelectasis, pneumonia, aspiration pneumonitis or severe respiratory insufficiency. A thrombo-embolic complication was one episode of either ilio-femoral thrombosis or pulmonary embolism. Complications affecting the gastro-intestinal tract were either stress ulceration leading to clinically observed gastro-intestinal haemorrhage or prolonged paralytic ileus which delayed institution of enteral feeding. No patient suffered significant gastric dilatation. Genito-urinary complications tabulated included only acute infectious episodes, bacteruria associated with pyrexia, pyelonephritis or acute epididymo-orchitis. Pressure sores were recorded by anatomic location and depth and four grades were coded: cutaneous erythema only, partial thickness skin loss, full thickness skin loss extending down to, but not involving the subcutaneous tissues, and subcutaneous soft tissue loss exposing underlying bone. In the present study only the first episode in each of the five types of complication was analyzed. Further details of the methodology for diagnosis of complications including analysis of concurrent complications in different systems and recurrent episodes in the same system are presented in a companion report. ${ }^{24}$

Infections of the genito-urinary tract were the most common complication, affecting $60.1 \%$ of patients. Respiratory complications affected $25.5 \%$ of patients and thrombo-embolic events $17.3 \%$, followed by pressure sores and gastro-intestinal complications which affected fewer patients. Of the five categories only thrombo-embolic complications were found to show a significant difference $\left(X^{2}, p=0.018\right)$ related to operative treatment, occurring more than twice as frequently in the operated patients as in the non-operated $(22.9 \%$ and $9.9 \%$, respectively).

The mortality rates and the time of the deaths are summarized in Table 15. A total of 21 patients died during the study period for an overall mortality rate of $10.1 \%$. Sixteen patients (7.7\%) died during the first hospitalization while five $(2.4 \%)$ died between the time of discharge and follow-up. Deaths after the follow-up period were excluded. When mortality rate during first hospitalization was examined in relation to treatment regime, there were 12 deaths in the non-operated group (13.0\%) as opposed to four (3.5\%) in the operated group, a significant difference $\left(X^{2}, p=0.026\right)$. Compared with the survivors, the 16 who died prior to discharge were older $(68.8 \%$ aged 51 years or more), had an increased frequency of cervical injuries ( $81.3 \%$ ), an increased frequency of complete cord injuries $(62.5 \%)$ and an increased incidence of respiratory complications $(50.0 \%)$. Seven (43.8\%) of the 16 patients who died prior to discharge had complete cervical cord injuries. Ten of the $16(62.5 \%)$ died of respiratory failure and a further $3(18.8 \%)$ died of pulmonary embolism, two in the operated group and one in the nonoperated group. Of the five patients dying after first discharge, three deaths were due to respiratory failure, one to pulmonary embolism and one patient committed suicide.

Mean lengths of hospital stay for patients surviving to first discharge (excluding the 16 deaths during the first admission) were 51.3 days and 45.9 days for the operated and non-operated groups respectively, which were not significantly different (2-tailed T-test, pooled variance estimate, $p=0.28$ ). Length of stay was also compared for patients with and without an operative fusion. Halo vest external fixation, which might be expected to hasten patient mobilization, was frequently used to manage cervical injuries and might have obscured an effect of surgery on length of stay as patients treated with halo vests were coded in the

Table 14: Frequency of Complications in the Operated and Non-Operated Groups

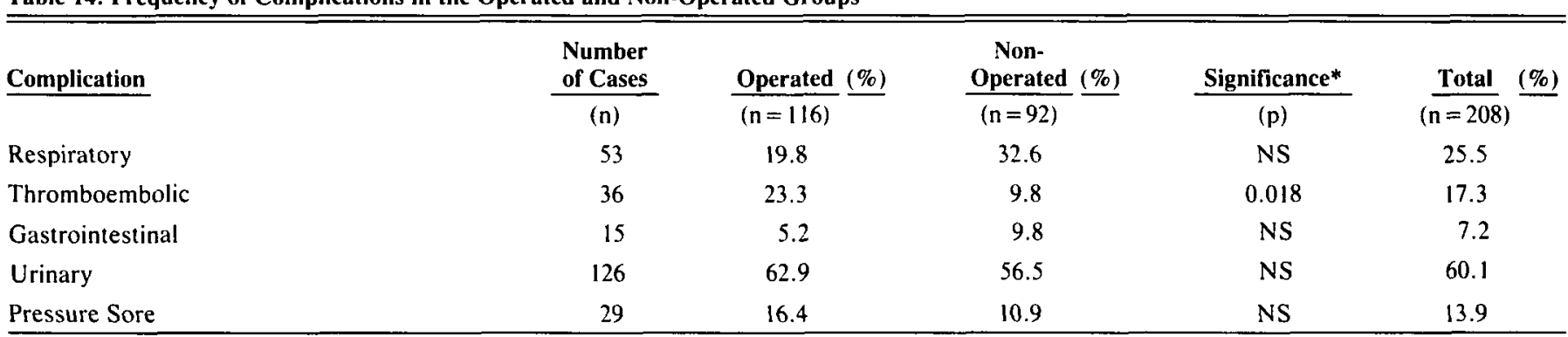

* $\mathrm{CHI}$ Square 
Table 15: Causes and Timing of Deaths in the Operated and Non-Operated Groups

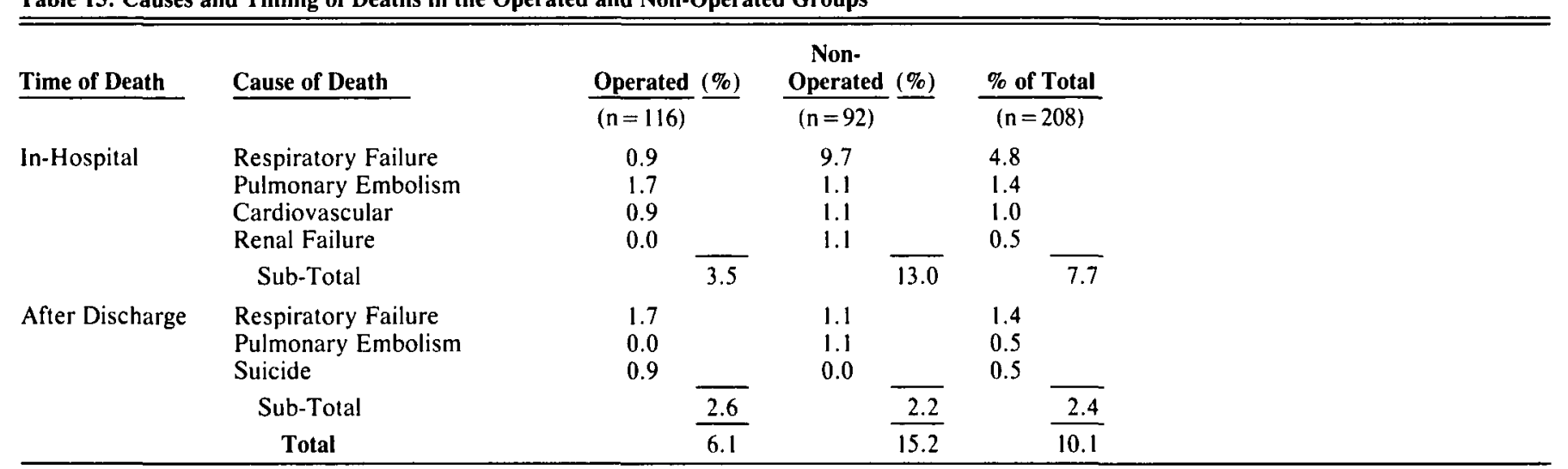

non-operative group. Therefore, patients having either a fusion or halo vest external fixation were grouped and the length of stay compared to patients managed without such stabilization of the spine. However, neither regrouping of patients demonstrated a significant effect on length of stay: all groups showed a mean duration of first hospitalization of between 45 and 50 days.

Neurological recovery was analyzed only in patients surviving to full follow-up, and thus the 21 patients who died before full follow-up, and the further 8 patients lost to follow-up, who did not meet the six or 12 month criteria, were excluded. For both the operated and non-operated groups there was an improvement in neurological function. Using the percent change method of assessment ${ }^{8}$ the operated and non-operated groups showed a mean change of $32.7 \%$ and $35.0 \%$, respectively which were not significantly different (2-tailed T-test, pooled variance estimate, $p=0.67$ ). When patients having a decompressive procedure were compared with the remainder of the patients, operated and non-operated, no significant difference in neurological recovery was found.

Multiple regression analysis was performed to determine the effect of surgical management on the three outcome variables, mortality, length of stay and neurological recovery (Table 16). For mortality, the age of the patient at the time of the accident and the total trauma load sustained (ISS) were the two variables found to be significantly associated with outcome. Mortality increased with increasing age and increasing severity of combined injuries. For length of stay, only the severity of the cord injury was significantly related, length of stay increasing with increasing severity of cord injury. Neurological recovery was significantly affected by the severity of the cord injury and the combined trauma burden. Improved recovery was related to decreasing severity of cord injury, and reduced total trauma load. The treatment regime, whether the patient was treated surgically or conservatively, was not associated with any of the three outcome parameters.

Additional, more detailed statistical analysis was performed, but no other effect of treatment regime, surgical or non-surgical, on the outcome parameters was observed.

\section{Discussion}

Objective assessment of the results of surgical procedures performed in spinal cord injured patients is difficult due to the lack of randomized, prospective controlled studies. This funda- mental difficulty is partly related to the multitude of combinations presented by the injury itself, as well as the numerous operative methods advocated for patient management. Important variables include patient age, cause of injury, time interval after injury, associated injuries, the level and serverity of the cord injury and the type of vertebral column injury. ${ }^{23}$ With respect to operative management, the timing and type of procedure are other important variables. Finally, there is the additional major problem of selecting the appropriate method of management of the non-surgical control group. Indeed, to the authors' knowledge there has never been a randomized prospective controlled study of the value of any surgical procedure in patients with acute spinal cord injury. Most studies attempting to define the place of surgery in the management of spinal cord injured patients have compared a group of patients treated by a single method with either a historical control group from the same institution or from the literature treated by another method. Although the two recent studies cited previously ${ }^{4.5}$ compared concurrent surgical and non-surgical groups, neither addressed the problem of variability between the patients entering each treatment limb when discussing differences in outcome parameters. With respect to non-surgical studies of acute spinal cord injured patients, the same difficulties of randomization have contributed to the paucity of controlled studies. ${ }^{25}$

In the present report, although the data were collected prospectively, patients were not randomly assigned to treatment groups. However, in this and companion reports ${ }^{6.24 .26 .27}$ objective data collection and statistical techniques were used which partly compensate for this lack of randomization in the

Table 16: Results of Multiple Regression Analysis Significant Independent Varialles $(\mathbf{p}<0.05)$

\begin{tabular}{|c|c|c|c|c|}
\hline Dependent Variable & First & [t] & Second & [t] \\
\hline Mortality & Age & 7.17 & ISS & 3.17 \\
\hline Length of Stay & Grade & 2.93 & - & - \\
\hline $\begin{array}{c}\text { Neurological } \\
\text { Recovery }\end{array}$ & Grade & 3.46 & ISS & 2.56 \\
\hline
\end{tabular}

Independent Variables Included in Analysis

Age $=$ Age at Time of Injury

Level $=$ Level of Spinal Injury

Fracture $=$ Type of Bony Vertebral Injury

Grade $=$ Severity of Spinal Cord Injury

ISS = Injury Severity Score

Operate $=$ Treatment, Surgical or Non-Surgical 
study design. Firstly, standard statistical methods were used to determine significant differences between the operated and non-operated groups for ten admission parameters. Secondly, a similar analysis was performed to identify significant differences between the groups for three outcome variables. Finally, multiple regression techniques were used to determine whether differences between the initial condition of patients entering each group or effects of treatment accounted for any differences noted in outcome variables.

In the operated and non-operated groups there was no significant difference in seven of the 10 variables describing the patients on admission: age, sex, distance travelled to admission to the Unit, time interval occasioned by the transfer, type of accident causing the injury, severity of injury to the spinal cord and severity of associated injuries. However, there were significant differences between the groups in the rrequency of injuries at different levels of the vertebral column, the type of vertebral column injury and the frequency of pre-existing spinal disease. For example, patients with cervical injuries had the lowest incidence of surgery and the frequency of surgical intervention increased the more caudal the lesion (Table 3 ). The relative infrequency of surgical procedures in patients with cervical injuries was largely due to the early establishment in the Unit of a halo program and the effectiveness of halos for restoring and maintaining cervical alignment. ${ }^{12.13}$ These patients were usually effectively treated with halo traction for reduction and immobilization of the spine, and then were mobilized in the halo vest.

The type of bony injury to the vertebral column also influenced the decision to operate. Patients with normal radiographs or with $\mathrm{x}$-rays showing dislocation without fracture, who together comprised about $10 \%$ of the total number of patients, had a low frequency (about $20 \%$ ) of operative treatment (Table 4). These injuries were reduced, if necessary, by non-operative methods, generally did not require surgery for residual compression of the cord or nerve roots, and most were considered stable enough to allow mobilization of the patient without operative fusion. The more extensive bony injuries, including fracture-dislocations, compression and burst fractures, which comprised about $83 \%$ of all injuries, were more likely to result in surgical treatment, with $59 \%$ to $76 \%$ of cases undergoing surgery depending on the fracture type (Table 4). The high frequency of surgical management of these cases suggests that the surgeons considered such injuries unstable or difficult to reduce or to maintain in reduction non-operatively, or they identified associated compression of the cord or nerve roots which required surgical relief either as the primary treatment or after non-operative methods had been tried unsuccessfully.

The presence of pre-existing spinal column conditions lead to a reduced frequency of operation. Most of these patients were older and had cervical spondylosis. Typically, the patient was admitted after a domestic fall and had a cervical injury with an incomplete cord lesion with no evidence of trauma to, or only minor fracturing of, the vertebral column. This combination of factors usually lead to a decision for non-operative management.

Thus, in three of 10 clinical variables there were differences at admission between the surgical and non-surgical groups. The reasons for these differences are the management principles in effect in the Unit at the time of the study. For example, the fact that the non-operated group included more patients with cervical injuries with and without pre-existing spinal abnormalities, reflects the management principle that halo traction followed by mobilization in the halo-vest is effective treatment for this patient population. Conversely, the operated group had more patients with major disruption of the spinal column reflecting the management principle of surgically treating unstable or compressing bony lesions. Thus, the operated and non-operated groups represent populations selected according to principles of management in effect at the time, and comparison of outcome between these groups must take into account this selection of individual patients for a particular treatment regime.

Two recent reports analyzed the types and frequency of surgical procedures in spinal injuries ${ }^{4.5}$ and their findings are roughly in agreement with those presented here. About $75 \%$ of patients with thoraco-lumbar fracture and cord injury had a spinal operation, which is comparable to the $77 \%$ of patients in the present series with injuries below $\mathrm{T} 1$ who were treated surgically. The main trends identified by these authors, including the decreasing incidence of laminectomy alone and the increasing use of fusion techniques, were also found in the present study. Indeed, in our study only $5 \%$ of patients had a laminectomy alone, and $95 \%$ of patients undergoing a surgical procedure also had a fusion.

Study of the effect of the treatment regime on the complication rates indicates that surgery significantly increased the incidence of thrombo-embolic but not the other complications (Table 14), and this is in agreement with the report of Ahn et al. ${ }^{4}$ Although the numbers involved are small, the increased predisposition to thrombo-embolic complications did not appear to cause increased deaths from pulmonary embolism in the operated group. Two of the four deaths prior to discharge in the operated group were due to pulmonary embolism, one 16 days after surgery while the other occurred after eleven months, following a long hospitalization and multiple complications. There were two deaths from pulmonary embolism in the nonoperated group. The low hospital mortality rate $(3.5 \%)$ in the operated group indicates that surgery does not endanger survival in spinal cord injured patients.

The increased mortality rate in the non-operated patients most likely reflects the selection of certain patients for nonoperative treatment, especially those with cervical injuries. In a companion report ${ }^{24}$ we have shown, for the same group of patients, firstly, that patients with cervical injuries have a significantly increased frequency of respiratory complications and, secondly, that the presence of respiratory complications is associated with an increased mortality rate. Indeed, 10 of the 12 hospital deaths in the non-operative group occurred in cervical injuries, and eight of these were from respiratory failure.

In contrast to other reports ${ }^{4,5}$ which found that surgery reduced the length of hospitalization, the present study found no significant difference in the length of stay for those patients undergoing operation. There was no significant difference in the degree of neurological recovery between the two treatment groups when assessed by the percent change method: the mean percent improvement was $32.8 \%$ for the operated patients and $34.8 \%$ for the non-operated patients. Even when the analysis was restricted to patients having decompressive procedures, no benefit could be identified.

These findings can be interpreted in several ways. Firstly, that the surgical procedures had no effect on these outcome parameters. Secondly, that operative treatment did not harm the patients or compromise neurological recovery. Morgan et 
$\mathrm{al}^{28}$ have reported cases where a particular procedure, laminectomy, was associated with neurological deterioration in patients with incomplete cord lesions. A third interpretation is that operative treatment was successful in improving the recovery of selected cases to the same extent as in the non-operated cases, assuming that such recovery would not have occurred without surgery.

We have shown in a companion paper ${ }^{6}$ that there has been an improvement in neurological recovery and a marked reduction in the length of acute hospital stay for the patients examined in the present study as compared with a historical control group managed in the same institution. Surgical treatment may be one of the reasons for these improvements, although other factors may also be important, such as the use of halo vests. However, we have not been able to quantify such benefit in the present study of concurrently treated patients. Therefore, the value of surgery in the management of spinal cord injury remains undefined and must await the performance of a rigorously controlled, randomized, prospective study.

\section{ACKNOWLEDGEMENTS}

This study was supported by a Demonstration Model Grant (DM 201) from the Ministry of Health, Province of Ontario. C.H. Tator was the founder and Head of the Acute Spinal Cord Injury Unit at Sunnybrook Medical Centre from 1974 to 1985. E.G. Duncan was a Clinical Research Fellow in the Division of Neurosurgery at the Toronto Western Hospital. Grateful acknowledgement is made to several staff members of the Sunnybrook and Toronto General Hospitals, especially Drs. D.W. Rowed and M.L. Schwartz, for allowing us to include patients admitted under them in this study. The help of Maria Vespa and Kim Gilmour with manuscript preparation is noted with thanks.

\section{REFERENCES}

I. Guttmann L. Spinal cord injuries: Comprehensive management and research. 1973. Blackwell, Oxford.

2. Ducker TB, Saul TS. The poly-trauma and spinal cord injury. In: C.H. Tator ed. Early Management of Acute Spinal Cord Injury. Raven Press, New York 1982; 53-58.

3. Bedbrook GM. Spinal injuries with tetraplegia and paraplegia. J Bone Joint Surg (B) 1979; 61: 267-84.

4. Ahn JH, Ragnarsson KT, Gordon WA et al. Current trends in stabilizing high thoracic and thoracolumbar spinal fractures. Arch Phys Med Rehab 1984; 65: 366-369.

5. Wilmot CB, Hall KM. Evaluation of acute surgical intervention in traumatic paraplegia. Paraplegia 1986; 24: 71-76.

6. Tator CH, Duncan EG, Edmonds VE, Lapczak LI, Andrews DF. Demographic analysis of 552 patients with acute spinal cord injury in Ontario, Canada from 1948 to 1981. In preparation.

7. Tator CH, Rowed DW. Current concepts in the immediate management of acute spinal cord injuries. Can Med Assoc J 1979; 121: 1453-1464.

8. Tator CH, Rowed DW, Schwartz ML. Sunnybrook cord injury scales for assessing neurological injury and neurological recovery.
In: C.H. Tator (ed). Early Management of Acute Spinal Cord Injury. Raven Press, New York 1982; 7-24.

9. Baker SP, O'Neill B, Haddon W. Lomg WB. The injury severity score: A method for describing patients with multiple injuries and evaluating emergency care. J Trauma 1974; 14: 187-196.

10. Greenspan L, McLellan BA, Greig H. Abbreviated injury scale and injury severity score: A scoring chart. J. Trauma 1985: 25: 60-64.

11. Rowed D. Value of somatosensory evoked potentials for prognosis in partial cord injuries. $\mathrm{ln}$ : C.H. Tator (ed). Early Management of Acute Spinal Cord Injury. Raven Press. New York 1982: 167.180.

12. Tator CH, Ekong CEU, Rowed DW, Schwartz ML. Edmonds VE. Halo devices for the treatment of acute cervical spinal cord injury. In: C.H. Tator (ed). Early Management of Acute Spinal Cord Injury. Raven Press, New York 1982: 231-256.

13. Edmonds VE, Tator $\mathrm{CH}$. Coordination of a halo program for an acute spinal cord injury unit. In: C.H. Tator (ed). Early Management of Acute Spinal Cord Injury. Raven Press, New York 1982: 263-271.

14. Barkin M, Herschorn S, Comisarow RH. The urologic care of the spinal cord injured patient. In: C.H. Tator ed. Early Management of Acute Spinal Cord Injury. Raven Press. New York 1982: 273-278.

15. Bharatwal N. Rehabilitation of cervical cord injuries in the acute phase. $I n$ : C.H. Tator ed. Early Management of Acute Spinal Cord Injury. Raven Press, New York 1982; 291-300.

16. Rowed DW, Tator $\mathrm{CH}$. Cervical spondylosis in acute cervical cord injuries. In: C.H. Tator ed. Early Management of Acute Spinal Cord Injury. Raven Press, New York 1982; 335-347.

17. Schwartz ML, Tator $\mathrm{CH}$, Rowed DW. Atlantoaxial trauma with spinal cord injury. In: C.H. Tator ed. Early Management of Acute Spinal Cord Injury. Raven Press, New York 1982;357-364.

18. Tator $\mathrm{CH}$, Ekong CEU, Rowed DW et al. Spinal injuries due to hockey. Can J Neurol Sci 1984; 11: 34-41.

19. Tator CH, Rowed DW. Schwartz ML et al. Management of acute spinal cord injuries. Can J Surg 1984: 27: 289-294.

20. Tator $\mathrm{CH}$, Edmonds VE. National survey of spinal injuries in hockey players. Can Med Assoc J 1984; 130: 875-880.

21. Ekong CEU, Tator $\mathrm{CH}$. Spinal cord injury in the work force. Can J Surg 1985; 28: 165-167.

22. Tator $\mathrm{CH}$, Edmonds VE. Sports and recreation are a rising cause of spinal cord injury. Phys and Sports Med 1986: 14: 157-167.

23. Tator $\mathrm{CH}$. Spine-spinal cord relationships in spinal cord trauma. Clin Neurosurg 1983; 30: 479-494.

24. Tator CH, Duncan EG, Edmonds VE, Lapczak LI, Andrews DF. Early morbidity and mortality after acute spinal cord injury. In preparation.

25. Bracken MB, Collins WF, Freeman DF et al. Efficacy of methylprednisolone in acute spinal cord injury. JAMA 1984:251:45-51.

26. Tator CH, Duncan EG, Edmonds VE, Lapczak LI, Andrews DF et al. Factors affecting the cost of early management following acute spinal cord injury. In preparation.

27. Tator CH, Duncan EG, Edmonds VE, Lapczak LI. Andrews DF. Utility of an anatomical injury severity score in predicting outcome for patients with acute spinal trauma and associated injuries. In preparation.

28. Morgan TH, Wharton GW, Austin GN. The results of laminectomy in patients with incomplete spinal cord injuries. Paraplegia 1971; 9: 14-23. 